\title{
Functional disorders continue to pose diagnostic and therapeutic challenges to neurologists
}

\author{
Distúrbios funcionais continuam a representar desafios diagnósticos e terapêuticos para \\ os neurologistas
}

Luiz Henrique Martins Castro

Departamento de Neurologia, Faculdade de Medicina, Universidade de São Paulo, São Paulo SP, Brazil.

\section{Correspondence:}

Luiz Henrique Martins Castro; Av. Dr. Enéas de Carvalho Aguiar, $255 / 5^{\circ}$ andar / sala 5131; 05403-900 São Paulo SP; Brasil;

E-mail: castrolh@usp.br

Conflict of interest:

There is no conflict of interest to declare.

Received 29 August 2014 Accepted 17 September 2014
A lthough recognized by physicians since ancient times, functional disorders came to modern neurology scrutinity with Charcot's observations at the Salpêtrière in the late XIXth Century, when these disorders also came to the attention of a young Viennese neurologist, Sigmund Freud. Freud's approach to these disorders were the initial steps that led to the psychoanalytic theories and models ${ }^{1}$.

Common presentations of functional disorders include nonepileptic psychogenic seizures, psychogenic movement disorders, psychogenic syncope, psychogenic paralysis, balance disorders, blindness, memory loss, and dissociative states.

Functional disorders are frequently seen in neurology practice. Nonepileptic psychogenic seizures may represent up to $20 \%$ of patients with refractory epilepsy referred to an epilepsy monitoring unit, with a reported incidence of $4 \%$ of that of epilepsy ${ }^{2}$.

Conversion is the most common diagnosis underlying psychogenic disorders ${ }^{3}$. Other psychiatric conditions may coexist, such as personality disorders or traits, anxiety and depression ${ }^{4}$. A history of psychological trauma (including sexual trauma, neglect, verbal and physical abuse) has been associated with psychogenic disorders ${ }^{5}$. Compared to people with epilepsy, patients with psychogenic nonepileptic seizures present more severe and disabling seizures, as well as poorer quality of life ${ }^{2}$.

Establishing a correct diagnosis requires skilled history taking, physical and neurologic exam. Coexisting neurologic disease may render the diagnostic process even more challenging, and may deceive even the experienced neurologist. More recently, the use of neurophysiologic monitoring tests has lent further support for the diagnosis of some of these conditions.

Video-EEG monitoring has become a gold standard for the diagnosis of nonepileptic psychogenic seizures. Electrophysiologic analysis of abnormal movements has also become an important diagnostic tool for psychogenic movement disorders. Tilt-table testing also allows the diagnosis of psychogenic syncope.

Suggestion plays an important role in inducing psychogenic symptoms, but the use of provocative maneuvers for diagnostic purposes has been questioned under ethical grounds.

Diagnostic pitfalls for psychogenic disorders are numerous. Epileptic seizures may not be easily distinguished from psychogenic nonepileptic seizures even with video-EEG monitoring, since an eletrographic correlate may be lacking in hypermotor or other seizure types. In addition, psychogenic symptoms may emerge in the office and during the diagnostic process, and may not represent patient's habitual symptoms. Symptom embellishment or de novo emergence of psychogenic symptoms in the presence of a physician may mislead the physician to a diagnostic error ${ }^{6}$.

The diagnostic and therapeutic processes of psychogenic disorders involve cooperation between neurologists and psychiatrics. The neurologist is faced with the difficult challenge of diagnosing the functional nature of neurologic symptoms, as well as with ruling out 
neurologic disorders, that may occur as comorbidities. The psychiatrist should establish the psychiatric diagnoses and guide treatment.

Disclosing the diagnosis of a psychogenic disorder is a key step in the therapeutic process. Initially, symptoms must be validated. Psychogenic symptoms observed by the neurologist must be recognized as occurring in daily life, and as associated with impaired quality of life.

The importance of adequate diagnostic communication cannot be understated. The diagnostic communication of a psychogenic condition should be performed by an experienced physician, who must be able to create an atmosphere of empathy and support, and should also be able to recognize and deal with psychological mechanisms, such as resistance, that may emerge during diagnosis disclosure. Presenting the diagnosis in the inappropriate setting (such as in the emergency department), or in a hasty and unskilled manner may hinder the success of a therapeutic intervention.

Treatment for psychogenic disorders usually involves psychotherapeutic approaches, but evidence-based of efficacy is scarce. A pilot randomized controled trial of sertraline versus placebo for nonepileptic psychogenic seizures suggested a beneficial effect of the serotoninreuptake inhibitor, but the study was underpowered to prove the superiority of sertraline compared to placebo to decrease occurrence of psychogenic seizures ${ }^{7}$. A recent pilot randomized controlled trial showed significant seizure reduction and improved comorbid symptoms and global functioning for psychogenic nonepileptic seizure patients that underwent cognitive behavioral treatment with or without sertraline, while treatment-as-usual or sertralineonly showed no benefit ${ }^{8}$.

In this issue of Arquivos de Neuropsiquiatria, DePaola et al. provide an extensive review of historical aspects, epidemiology, clinical features, diagnosis, and prognosis of psychogenic nonepileptic seizures and psychogenic movement disorders?.

The authors also review the limited published data that analyzed possible common features of both disorders. Studies were limited by their retrospective nature or small sample size ${ }^{10,11}$. A prospective study of demographic, clinical and psychometric questionnaires of psychogenic nonepileptic seizure and psychogenic movement disorders patients disclosed similiar psychological profiles with decreased physical and mental health scores and increased somatization, depression and anxiety scores for psychogenic nonepileptic seizures and psychogenic movement disorders. Despite differences in gender, age and clinical presentation, the authors suggested that both conditions may not represent distinct entities ${ }^{12}$. These findings should be replicated with different methodologies and in different patient populations, preferably in collaborative studies.

The authors also review recent advances in evidence-based efficacy of cognitive behavioral therapy for psychogenic nonepileptic seizures ${ }^{8}$. These studies should be replicated with different populations, in other cultural settings, and in patients with other types of psychogenic disorders, where evidence-based treatment data are still scarce ${ }^{13}$.

\section{References}

1. Goetz CG, Bonduelle M, Gelfand T. Hysteria. In: Goetz CG, Bonduelle M, Gelfand T. Charcot, editors. Constructing neurology. New York: Oxford University Press; 1995. p. 172-216.

2. Krumholz A, Hopp J. Psychogenic (nonepileptic) seizures. Semin Neurol. 2006;26(3):341-50. http://dx.doi.org/10.1055/s-2006-945520

3. Rowe JB. Conversion disorder: understanding the pathogenic links between emotion and motor systems in the brain. Brain. 2010;133(Pt 5):1295-9. http://dx.doi.org/10.1093/brain/awq096

4. Marchetti RL, Kurcgant D, gallucci Neto J, Bismark MA, Marchetti LB, Fiore LA. Psychiatric diagnoses of patients with psychogenic nonepileptic seizures. Seizure. 2008;17(3):247-53. http://dx.doi.org/ 10.1016/j.seizure.2007.07.006

5. Proença IC, Castro LH, Jorge CL, Marchetti RL. Emotional trauma and abuse in patients with psychogenic nonepileptic seizures. Epilepsy Behav. 2011;20(2):331-3. http://dx.doi.org/10.1016/j.yebeh.2010.11.015

6. Avbersek A, Sisodiya S. Does the primary literature provide support for clinical signs used to distinguish psychogenic nonepileptic seizures from epileptic seizures? J Neurol Neurosurg Psychiatry. 2010;81(7):719-25. http://dx.doi.org/10.1136/jnnp.2009.197996

7. LaFrance WC Jr, Keitner GI, Papandonatos GD, Blum AS, Machan JT, Ryan CD et al. Pilot pharmacologic randomized controlled trial for psychogenic nonepileptic seizures. Neurology. 2010;75(13):1166-73.
8. LaFrance WC Jr., Baird GB, Barry JJ, Blum AS, Webb AF, Keitner GI et al. Multicenter pilot treatment trial for psychogenic nonepileptic seizures. JAMA Psychiatry. 2014 [Epub ahead of print]. http://dx.doi. org/10.1001/jamapsychiatry.2014.817

9. De Paola L, Marchetti R, Teive HAG3, LaFrance Jr WC. Psychogenic nonepileptic seizures and psychogenic movement disorders: two sides of the same coin? Arq Neuropsiquiatr 2014;72:793-802.

10. Grimald I, Dubuc M, Kahane P, Bougerol T, Vercueil L. Anxiety and depression in psychogenic movement disorder and non-epileptic seizures: a prospective comparative study. Revue Neurol (Paris). 2010;166(5):515-22. http://dx.doi.org/10.1016/j.neurol.2009.10.016

11. Driver-Dunckley E, Stonnington CM, Locke DEC, Noe K. Comparison of psychogenic movement disorders and psychogenic nonepileptic seizures: Is phenotype clinically important? Psychosomatics. 2011;52(4):337-45. http://dx.doi.org/10.1016/j.psym.2011.01.008.

12. Hopp JL, Anderson KE, Krumholz A, Gruber-Baldini AL, Shulman LM. Psychogenic seizures and psychogenic movement disorders: are they the same patients? Epilepsy Behav. 2012;25(4):666-9. http://dx.doi. org/10.1016/j.yebeh.2012.10.007

13. Hinson VK, Weinstein S, Bernard B, Leurgans SE, Goetz CG. Singleblind clinical trial of psychotherapy for treatment of psychogenic movement disorders. Parkinsonism Relat Disord. 2006;12(3):177-80. http://dx.doi.org/10.1016/j.parkreldis.2005.10.006 